\title{
Ice-core researchers hope to chill out
}

\section{Fresh freezers needed to preserve ancient gas, scientists say.}

Researchers in the United States and Europe are seeking funding so that the ice cores used to study Earth's past climate can have the same luxuriously chilly storage facilities currently enjoyed by prize tuna.

The cylindrical cores, drilled at multi-milliondollar expense from polar and glacial ice, can be kilometres long. They contain tiny bubbles of trapped air, allowing scientists to measure the concentration of carbon dioxide in the atmosphere from hundreds of thousands of years ago. The relative ratios of oxygen and nitrogen, and their isotopes, can also reveal temperature variations and help to date the trapped gas.

But oxygen is gradually lost when ice cores are stored at $-20^{\circ} \mathrm{C}$ to $-30^{\circ} \mathrm{C}$, the standard temperature of current cold-storage facilities in the United States and Europe (M. Bender, T. Sowers and V. Lipenkov J. Geophys. Res. 100, 18651-18660; 1995).

The oxygen diffuses slowly toward the core's surface and can be lost to the air, resulting in

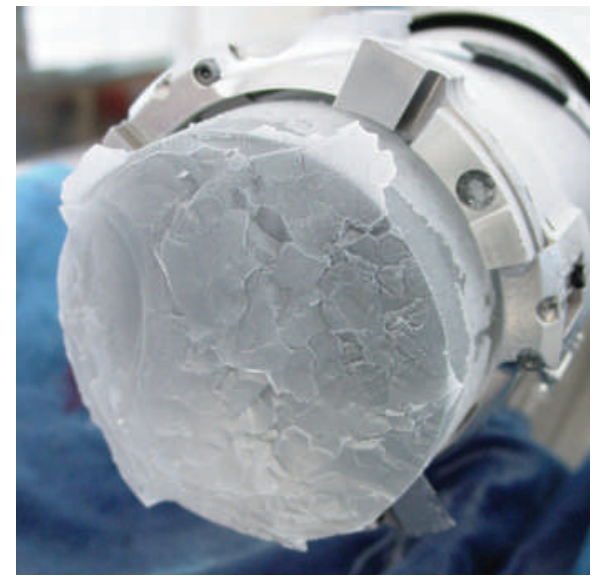

Unless stored correctly, ice cores lose their value.

higher ratios of nitrogen to oxygen that can distort the conclusions scientists draw from them. In 2005, Japanese researchers showed that colder storage temperatures could mitigate this gas loss (T. Ikeda-Fukazawa et al. Earth Planet.
Sci. Lett. 229, 183-192; 2005), and the ice-core storage facility at the National Institute of Polar Research, Tokyo, was subsequently upgraded with technology used to maintain cold stores for high-grade tuna at $-50^{\circ} \mathrm{C}$.

US researchers are now seeking roughly $\$ 5$ million to rebuild cold-storage facilities at the US Army Cold Regions Research and Engineering Laboratory in Hanover, New Hampshire, which would also have its storage capacity increased by about $25 \%$. Ian Baker, a materials scientist at Dartmouth College, also in Hanover, is leading the application for funding from the National Science Foundation. If the team gets its funding, Dartmouth would then manage the refurbished facility, which could be completed by 2010 .

European scientists face a similar challenge. "We need a European-wide facility," says Eric Wolff at the British Antarctic Survey in Cambridge, UK. But a European Commission study in 2008 estimated that a new $-50^{\circ} \mathrm{C}$ facility, with associated research labs and teaching facilities,

\section{Flu database rocked by legal row}

\section{EXCLUSIVE}

A question mark is hanging over the future of EpiFlu, an international database created to help monitor the spread and evolution of influenza viruses. The database openly shares genetic, epidemiological and clinical data that previously had often been hoarded by countries and scientists, and is contributing to the rapid analysis of viral gene sequences from the current H1N1 pandemic.

EpiFlu has become mired in a legal dispute between the Global Initiative on Sharing Avian Influenza Data (GISAID), an international group created by leading flu researchers in August 2006 to promote data sharing (see Nature 442,981; 2006), and the Swiss Institute of Bioinformatics (SIB) in Geneva. GISAID announced a contract with the SIB in December 2006 to build the EpiFlu database. Most funding for EpiFlu came from the US Centers for Disease Control and Prevention and the Swiss government.

The row became public on 27 July, when visitors to the EpiFlu landing page on the GISAID website were met with a message from the SIB informing them that the database was currently unavailable on that site "due to contractual and legal issues", and instead was available only to users redirected to a SIB website. The same day, the SIB e-mailed the same message to all registered users of the database.

The next day, GISAID also e-mailed users to assert that the SIB "had no right [to cut off the access to the EpiFlu Database via GISAID] or to operate the EpiFlu Database on its own".

Both SIB and GISAID officials declined to discuss the details because of the ongoing legal dispute. But the SIB alleges that GISAID has breached its contract by failing to pay its bills on time. GISAID officials say that although there had been a hiatus in its funding, they had acted in good faith and had subsequently obtained additional funds to meet some of the bills.

"GISAID continues to work with the SIB to resolve their monetary dispute," says Cheryl Bennett, an official at the GISAID Foundation's Washington DC office. "However, before the monetary dispute can fairly be resolved, GISAID must receive an accurate accounting from the SIB, which GISAID has requested but the SIB has thus far not provided."
She asserts that the SIB's continued operation of the database, including GISAID's trademark logos and data-access agreement, amounts to "misappropriation" of the database, and claims that under the terms of the contract, all EpiFlu data remain GISAID's property, giving the SIB no right to operate the database independently.

However, the SIB had written to GISAID in September 2008 declaring that it was terminating their contract. The SIB argues that GISAID has not settled its bills in full and that, under Swiss law, a default on payment renders a contract null and void, giving the SIB the rights to the database it built.

"I hope they reach Since then, the SIB claims that it the best solution has operated the database without for the sake of asking for more money from global health." GISAID, and has taken fund-raising for the database into its own hands. Although researchers can still access the database, public-health officials are worried by the longer-term implications of the row. Before the creation of GISAID, several countries - including Indonesia, an avian flu hotspot - had refused to share sequence data on the grounds that they got little in return. But they 
would cost $€ 25$ million (US\$35 million), and is unlikely to be funded, says Frank Wilhelms of the Alfred Wegener Institute for Polar and Marine Research in Bremerhaven, Germany, which houses one of four major ice-core facilities in Europe. The International Partnerships in Ice Core Sciences (IPICS), an organization of scientists, drillers and engineers from 18 nations, has also said that urgent action is needed to prevent ice cores degrading.

In the interim, Jeffrey Severinghaus, an IPICS steering-committee member from the Scripps Institute of Oceanography in La Jolla, California, says some institutions like his are building smaller units to keep parts of cores at $-50^{\circ} \mathrm{C}$. These units can be created for about $\$ 15,000$, but the necessary freezer adaptations void warranties and there are concerns that keeping sections of ice cores in many different locations may hamper researchers' access.

His lab is currently studying oxygen/nitrogen ratios in ice cores drilled last year for the Western Antarctic Ice Sheet Divide Ice Core project, a collaboration of US research groups. Preliminary comparisons with the Byrd ice core, drilled in 1968 in Western Antarctica, show that oxygen has been lost in the older core during storage, he says.

Rex Dalton

were persuaded to share by GISAID's terms of access, similar to those of open-source software, in which all users agree to share their own data and give due credit to the originators.

"Indonesia has been supportive of GISAID from the outset," says Widjaja Lukito, a senior policy adviser at the country's ministry of health. He adds that he is watching "with great concern the problems faced by the GISAID Initiative during this pandemic phase". He says that he strongly hopes that "the parties involved will reach the best solution for the sake of global public health".

One flu scientist, who is a member of GISAID's scientific council, adds that EpiFlu is more than just the database computing infrastructure built by the SIB. Considerable effort has been invested by GSAID and its partners in "building trust" between the scientific community and countries who have sequence data to deposit, and in contributing influenza expertise.

Lawyers for both the SIB and GISAID have in the past weeks made confidential settlement offers to each other, and both say they are keen to reach a peaceful settlement. "The SIB is $100 \%$ committed to the EpiFlu database as part of the GISAID initiative. We are working very hard to find the best possible solution for all concerned," says Ron Appel, head of the SIB.

Declan Butler

\section{Climate data spat intensifies}

A leading UK climatologist is being inundated by freedom-of-information-act requests to make raw climate data publicly available, leading to a renewed row over data access.

Since 2002, Steve McIntyre, the editor of Climate Audit, a blog that investigates the statistical methods used in climate science, has repeatedly asked Phil Jones, director of the Climatic Research Unit (CRU) at the University of East Anglia, UK, for access to monthly global surface temperature data held by the institute. But in recent weeks, Jones has been swamped by a sudden surge in demands for data.

Several organizations worldwide collect and report global average temperature data for each month. Of these, a temperature data set held jointly by CRU and the UK Met Office's Hadley Centre in Exeter, known as HadCRU, extends back the farthest, beginning in 1850. Although these data are made available in a processed format that shows the global trend, access to the raw data is restricted to academics.

Between 24 July and 29 July of this year, CRU received 58 freedom-of-informationact requests from McIntyre and people affiliated with Climate Audit, requesting access to the data or information about their use. In the past month, the UK Met Office, which receives a cleaned-up version of the raw data from CRU, has received ten requests of its own.

McIntyre, based in Toronto, Ontario, is best known for questioning the validity of the statistical analyses used to reconstruct the past 1,000 years of climate, but has more recently turned his attention to criticizing the quality of global temperature records. Jones concedes that raw climate data have imperfections - such as duplication of stations - but says that such minor errors would not alter the overall global temperature trend. McIntyre insists that he is not interested in challenging the science of climate change or in nit-picking, but is simply asking that the data be made available. "The only policy I want people to change is their data-access policy," he says.
Jones says he can't fulfil the requests because of confidentiality agreements signed in the 1990s with some nations, including Spain, Germany, Bahrain and Norway, that restrict the data to academic use. In some cases, says Jones, the agreements were made verbally, and in others the written records were mislaid during a move.

He says he is now working to make the data publicly available online. As Nature went to press, Jones was expected to post a statement on the CRU website to that effect, including any existing confidentiality agreements. Jones says any such data release "needs to be done in a systematic way".

"We're trying to make them all available," says Jones. "We're consulting with all the meteorological services - about 150 members [of the World Meteorological Organization] - and will ask them if they are happy to release the data." A spokesperson for the Met Office confirmed this, saying "we are happy for CRU to take the lead on this, as they are their data".

But getting the all-clear from other nations won't be without its challenges, says Jones, who estimates that it could take several months. In addition, some nations may object if they make money by selling their wind, sunshine and precipitation data.

The dispute is likely to continue for some time. McIntyre is especially aggrieved that Peter Webster, a hurricane expert at the Georgia Institute of Technology in Atlanta, was needs to be done in a systematic way." recently provided with data that had been refused to him.

Webster says his team was given the station data for a very specific request that will result in a joint publication with Jones. "Reasonable requests should be fulfilled because making data available advances science," says Webster, "but it has to be an authentic request because otherwise you'd be swamped."

Indeed, Jones says he has become "markedly less responsive to the public over the past few years as a result of this". Olive Heffernan 